\title{
White blood-cell count and the risk of impaired fasting glucose or Type II diabetes in middle-aged Japanese men
}

\author{
N. Nakanishi ${ }^{1}$, H. Yoshida ${ }^{1}$, Y.Matsuo ${ }^{1}$, K. Suzuki ${ }^{2}$, K. Tatara ${ }^{1}$ \\ ${ }^{1}$ Department of Social and Environmental Medicine, Course of Social Medicine, Osaka University Graduate School of Medicine, \\ Osaka, Japan \\ ${ }^{2}$ Japan Labour and Welfare Association, Tokyo, Japan
}

\section{Abstract}

Aims/hypothesis. To investigate the association between white blood-cell (WBC) count and the development of diabetes, independent of cigarette smoking.

Methods. We examined 2953 Japanese men who were office workers and between 35 and 59 years of age and who did not have impaired fasting glucose (IFG) (a fasting glucose concentration of $6.1-6.9 \mathrm{mmol} / \mathrm{l}$ ), Type II (non-insulin-dependent) diabetes mellitus (a fasting glucose concentration of $\geq 7.0 \mathrm{mmol} / \mathrm{l}$ or more or receipt of hypoglycaemic medication), medication for hypertension, and a history of cardiovascular disease. Fasting glucose concentrations were measured at annual health examinations from May 1994 through May 2000.

Results. After controlling for potential predictors of diabetes, the relative risk for IFG or Type II diabetes mellitus compared with a WBC count of less than $5.3 \cdot 10^{9}$ cells $/ 1$ was $1.2(95 \%-\mathrm{CI}, 0.6-2.3), 1.6$ (CI,
0.8-3.1), and 2.5 (CI, 1.2-5.1) among non-smokers ( $p$ for trend $=0.009)$ : and $1.0(\mathrm{CI}, 0.4-2.5), 2.3(\mathrm{CI}$, 1.0-5.1), and 3.1 (CI, 1.4-7.1) among ex-smokers $(p$ for trend $=0.001$ ) with WBC counts of 5.3-6.1, $6.2-7.2$, and $7.3 \cdot 10^{9}$ cells/ 1 or more, respectively. Among current smokers, the respective multivariate-adjusted relative risks for IFG or Type II diabetes mellitus were 1.1 (CI, 0.6-2.1), 1.4 (CI, 0.8-2.4), and $1.2(\mathrm{CI}, 0.7-2.1)(p$ for trend $=0.460)$.

Conclusion/hypothesis. Although the selection of a rigorously normoglycaemic cohort might have had an influence on these observations, higher WBC counts seem to predict the development of IFG or Type II diabetes mellitus, primarily in non-smokers. [Diabetologia (2002) 45: 42-48]

Keywords Impaired fasting glucose, Type II (non-insulin-dependent) diabetes mellitus, incidence, white blood-cell count, cigarette smoking, longitudinal study, Japanese men.
Considerable research has been done on factors that influence the development of Type II (non-insulindependent) diabetes mellitus. Age, family history of

Received: 16 July 2001 and in revised form: 13 September 2001

Corresponding author: N. Nakanishi, Department of Social and Environmental Medicine, Course of Social Medicine, Osaka University Graduate School of Medicine F2, 2-2 Yamadaoka, Suita-shi, Osaka 565-0871, Japan, e-mail: noriyuki@ pbhel.med.osaka-u.ac.jp

Abbreviations: WBC, White blood cell; TNF, tumor necrosis factor; IL, interleukin; HDL, high-density lipoprotein; LDL, low-density lipoprotein diabetes, obesity, alcohol consumption, cigarette smoking, reduced physical activity, hypertension and dyslipidaemia have been confirmed as important predictors of Type II diabetes mellitus [1-11]. More recently, markers of low-grade inflammation have been shown to predict the occurrence of Type II diabetes mellitus $[12,13]$. Concentrations of inflammatory markers and mediators of inflammation - cytokines such as tumor necrosis factor (TNF)- $\alpha$ and interleukin (IL)-6 - are higher in patients with Type II diabetes mellitus, particularly in those with features of insulin resistance [14-16]. White blood cells (WBCs), another major component of the inflammatory process, are increased by cytokines, especially 
IL-6 [17]. The lipid pattern of high triglycerides and low high-density lipoprotein (HDL) cholesterol is a feature of inflammation and, more specifically, of TNF- $\alpha$ action [18]. Because some features of lowgraded inflammation such as glucose intolerance and dyslipidaemia are identical to the components of the insulin resistance syndrome [19], subclinical inflammation could be the expression of an insulin-resistant state, which would represent the underlying mechanism [20, 21].

Because smoking is associated with increases in WBC counts [22-25], WBC might serve as a biomarker for smoking rather than as a marker for an inflammatory response. An association between WBC count and the risk of diabetes has been observed previously $[12,13]$ but the relationship independent of smoking is not clear. Using data from serial annual health examinations at the workplace, we performed a longitudinal population study to examine prospectively the association of WBC count with development of impaired fasting glucose (IFG) or Type II diabetes mellitus (as diagnosed with the new revised criteria of American Diabetes Association in 1997 [26] for epidemiological studies) in normoglycaemic middle-aged Japanese men.

\section{Subjects and methods}

Study cohort. Our study is an ongoing cohort investigation, designed to clarify risk factors for major diseases, including hypertension, dyslipidaemia and diabetes among Japanese men who were office workers at one of the biggest building contractors in Japan. The Industrial Safety and Health Law in Japan requires the employer to conduct annual health examinations of all employees and this data is available for research in an anonymous form with the approval of the employer. To evaluate the association of WBC count with development of IFG or Type II diabetes mellitus, a survey of the incidence of IFG or Type II diabetes mellitus was done between 1994 and 2000. All male Japanese office workers between 35 and 59 years of age in May 1994 were invited to take a survey $(n=3694)$; the participation rate was $99.6 \%(n=3681)$.

Of the 3681 potential participants, no one was acutely ill. Altogether 663 (18.0\%) were excluded: 175 (4.8\%) had IFG, $282(7.7 \%)$ had Type II diabetes mellitus, 253 (6.9\%) were taking anti-hypertensive medication and $32(0.9 \%)$ had a past history of either coronary heart disease or stroke. Thus, the baseline population consisted of 3018 men. We also excluded 65 men who did not participate in consecutive annual health examinations during follow-up. The final study population for analysis therefore consisted of 2953 men. Men in whom IFG or Type II diabetes mellitus were found during repeated surveys through May 2000 were classified as having IFG or Type II diabetes mellitus. To determine the incidence of Type II diabetes mellitus, incidental cases of IFG were followed and were considered Type II diabetes mellitus if they reached that endpoint. Altogether 36 participants who started taking medication for diabetes during the observation period were considered to have Type II diabetes mellitus. Owing to the age range of the study population, all cases of IFG or Type II diabetes mellitus were diagnosed after 35 years of age.
Study design. Fasting plasma glucose concentrations and WBC counts were measured at annual health examinations in May from 1994 to 2000 . The participants were asked to fast for at least 8 hours and to avoid smoking and heavy physical activity for more than 2 hours before the examinations. Blood samples were drawn from an antecubital vein. Fasting plasma glucose concentrations were measured by the glucose dehydrogenase spectrophotometry with Olympus AU-5000 equipment in 1994 and Olympus AU-5200 equipment in 1995 to 2000 (Olympus Japan, Tokyo, Japan) by FALCO Biosystems Tokyo (Tokyo, Japan). WBC counts were determined using a Sysmex E-4000 autoanalyzer (Toa Medical Electronics, Tokyo, Japan). Quality control of the laboratory was done internally, and the coefficients of variation between and within assays for plasma glucose were no more than $3 \%$ from 1994 to 2000. Normal fasting glucose, IFG and Type II diabetes mellitus were defined using the criteria of American Diabetes Association [26]. Normal fasting glucose was defined as a fasting plasma glucose concentration of less than $6.1 \mathrm{mmol} / \mathrm{l}$. The criteria of IFG was a fasting plasma glucose concentration of 6.1-6.9 mmol/l. Type II diabetes mellitus was defined as a fasting plasma glucose concentration of $7.0 \mathrm{mmol} / 1$ or more or receipt of hypoglycaemic medications, because an oral glucose tolerance test was not performed in every subject.

Annual health examinations at study entry included medical history, physical examination, anthropometric measurements, biochemical measurements, and a questionnaire on health-related behaviours, such as smoking, alcohol consumption, and physical activity. Medical history and history of use of prescription drugs were assessed by the examining physicians. Family history of diabetes was defined as a mother, father, sister, or brother with diagnosed diabetes. The (BMI) was used as a measure of overall obesity and was calculated as body weight in kilograms divided by height in metres squared $\left(\mathrm{kg} / \mathrm{m}^{2}\right)$. After a 5-min rest in a quiet room, systolic and diastolic blood pressures were measured in the right arm by using a standard mercury sphygmomanometer. The Olympus AU5000 spectrophotometer was also used to measure total cholesterol, HDL cholesterol, triglyceride, and uric acid. Hematocrit was determined by using a Sysmex E-4000 autoanalyzer.

For health-related behaviour, the questionnaire asked about smoking habits (never, past or current smoker). Past or current smokers were asked about the number of cigarettes smoked each day and the duration of smoking in years. The questions about alcohol intake included items about the type of alcoholic beverage, the frequency of alcohol consumption per week and the usual amount consumed daily. Weekly alcohol intake was calculated and then converted to daily alcohol consumption (grams of ethanol per day) by using standard Japanese tables. Participants were asked about the type and weekly frequency of leisure time physical activity. Physical exercise was defined as participation in any physical activity, such as jogging, bicycling, swimming or tennis, which was performed long enough to work up a sweat.

Statistical analyses. The $\left(\chi^{2}\right)$ chi-square test and one-way analysis of variance were used to analyse the statistical differences among characteristics of the study participants at enrolment according to WBC count. Categories of WBC count were defined by the following quartiles: less than $5.3 \times 10^{9}$ cells $/ 1$, $5.3-6.1 \times 10^{9}$ cells $/ 1,6.2-7.2 \times 10^{9}$ cells $/ 1$, and $7.3 \times 10^{9}$ cells $/ 1$ or more. For each participant, person-years of follow-up were calculated from the date of enrolment to the date of the first incidence of IFG or Type II diabetes mellitus or the date of follow-up, whichever came first. The follow-up rate was $94.2 \%$ of the total potential person-years of follow-up. Cox's proportional hazards models were used to evaluate the association 
Table 1. Baseline characteristics of 2953 Japanese male office workers, according to white blood-cell count

\begin{tabular}{|c|c|c|c|c|c|}
\hline \multirow[t]{2}{*}{ Characteristics } & \multicolumn{4}{|c|}{ White blood cell $\left(\times 10^{9}\right.$ cells $\left./ 1\right)$} & \multirow[t]{2}{*}{$p$ value } \\
\hline & $\begin{array}{l}2.5-5.2 \\
(n=708)\end{array}$ & $\begin{array}{l}5.3-6.1 \\
(n=740)\end{array}$ & $\begin{array}{l}6.2-7.2 \\
(n=709)\end{array}$ & $\begin{array}{l}7.3-14.5 \\
(n=796)\end{array}$ & \\
\hline BMI $\left(\mathrm{kg} / \mathrm{m}^{2}\right)$ & $22.9 \pm 2.4$ & $23.3 \pm 2.6$ & $23.5 \pm 2.6$ & $23.6 \pm 2.8$ & $<0.001$ \\
\hline Family history of diabetes (\%) & 5.9 & 9.2 & 8.6 & 8.3 & 0.114 \\
\hline Current smokers (\%) & 25.3 & 43.2 & 56.3 & 78.8 & $<0.001$ \\
\hline $\begin{array}{l}\text { Physical exercise (times/week) \% } \\
\text { Hardly none } \\
\text { Once } \\
\text { Twice or more }\end{array}$ & $\begin{array}{l}44.6 \\
37.0 \\
18.4\end{array}$ & $\begin{array}{l}46.6 \\
40.3 \\
13.1\end{array}$ & $\begin{array}{l}48.0 \\
39.4 \\
12.7\end{array}$ & $\begin{array}{r}51.0 \\
39.7 \\
9.3\end{array}$ & $\begin{array}{r}0.089 \\
0.600 \\
<0.001\end{array}$ \\
\hline Systolic blood pressure (mmHg) & $124.5 \pm 13.7$ & $126.1 \pm 14.3$ & $127.6 \pm 13.9$ & $128.1 \pm 14.9$ & $<0.001$ \\
\hline Triglycerides (mmol/l) & $1.15 \pm 0.81$ & $1.35 \pm 0.88$ & $342 \pm 79$ & $1.72 \pm 1.32$ & $<0.001$ \\
\hline Uric acid $(\mu \mathrm{mol} / \mathrm{l})$ & $335 \pm 74$ & $345 \pm 76$ & $45.0 \pm 2.7$ & $345 \pm 80$ & 0.035 \\
\hline Hematocrit (\%) & $43.8 \pm 2.7$ & $44.6 \pm 2.6$ & $45.5 \pm 2.7$ & $45.5 \pm 2.7$ & $<0.001$ \\
\hline
\end{tabular}

Unless otherwise indicated, values are expressed as the means ( \pm SD)

between WBC count and development of IFG or Type II diabetes mellitus. Data were adjusted first for age alone, then for the following multiple covariates: age, BMI, alcohol consumption, physical activity, family history of diabetes, systolic blood pressure, and concentrations of fasting plasma glucose, total cholesterol, HDL cholesterol, triglyceride and uric acid, as well as hematocrit (model 1). Data were also adjusted for cigarette smoking (model 2). Potential confounding factors were treated as categorical variables: age, BMI, systolic blood pressure, fasting plasma glucose concentration, total cholesterol concentration, HDL cholesterol concentration, triglyceride concentration, uric acid concentration and hematocrit (all graded from 1 through 5 [first through fifth quintiles]); alcohol consumption (graded as 1 [none] or as quartile 1 [grade of 2] to quartile 4 [grade of 5] for drinkers); regular physical exercise (graded from 1 to 3 [hardly ever, once a week, or twice or more a week]); and family history of diabetes (no or yes). For cigarette smoking, the number of cigarettes smoked each day were graded from 1 to 3 for current smokers (first through third tertiles). The linear trends in risks were evaluated by entering indicators for each category of exposure.

Data were analysed by using the SPSS/PC statistical package (SPSS, Chicago, Ill., USA). All reported $p$ values are twotailed and those less than 0.05 were considered to be statistically significant.

\section{Results}

The baseline characteristics of the study sample according to WBC count are shown in Table 1. The mean BMI, systolic blood pressure, fasting plasma glucose concentration, total cholesterol concentration, HDL cholesterol concentration, triglyceride concentration, uric acid concentration and hemat- ocrit as well as the percentages of participants who smoked cigarettes currently and exercised twice or more a week differed significantly by WBC count. The BMI and uric acid concentration were lowest among men with a WBC count of less than $5.3 \times 10^{9}$ cells/l. Total cholesterol concentrations were highest among men with a WBC count of $7.3 \times 10^{9}$ cells/l or more. Systolic blood pressure, fasting plasma glucose concentration, triglyceride concentration, hematocrit and the percentage of current smokers increased as a WBC count increased. In contrast, HDL cholesterol concentrations and the percentage of men who exercised twice or more a week decreased as a WBC count increased. The mean age and diastolic blood pressure and the percentage of participants with a family history of diabetes and who drank alcohol currently did not differ significantly among the four groups.

Altogether 263 and 154 men developed IFG and Type II diabetes mellitus during the 15859 and 16263 person-years of follow-up, respectively. Incident rates per 1000 person-years for IFG and Type II diabetes mellitus increased as WBC count increased ( $p$ for trend $<0.001$ for both IFG and Type II diabetes mellitus) (Fig. 1).

To assess the effect of cigarette smoking on the association between WBC count and risk for diabetes, we studied the relation between WBC count and development of IFG or Type II diabetes mellitus according to smoking status (Table 2). As we assumed a similar mechanism for the development of IFG and Type II diabetes mellitus, IFG and Type II diabe- 


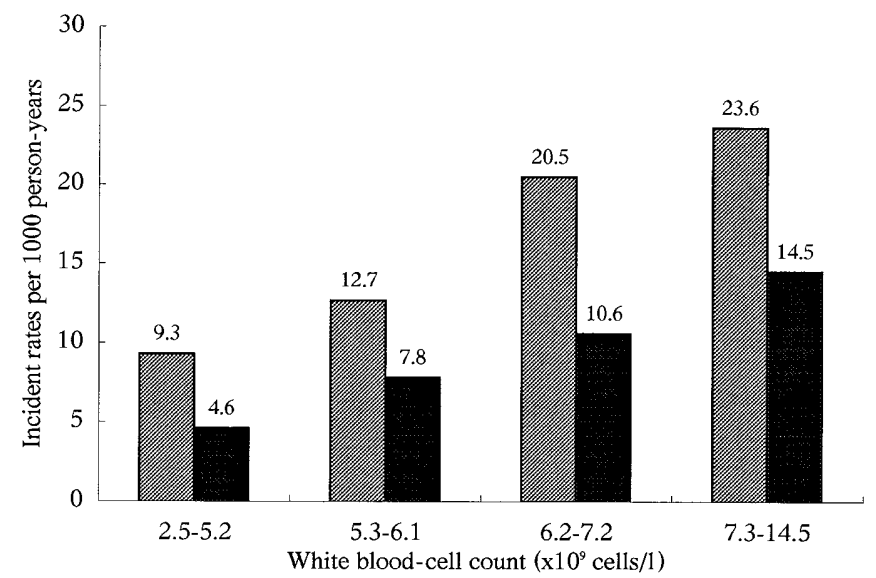

Fig. 1. Incidence rates per 1000 person-years for impaired fasting glucose and Type II diabetes mellitus according to white blood-cell count among 2953 Japanese male office workers during 6 years of follow-up. Impaired fasting glucose (ㅈ) Type II diabetes mellitus (

tes mellitus were combined. With adjustment for potential risk factors for diabetes - age, BMI, family history of diabetes, alcohol consumption, regular physical exercise, systolic blood pressure, fasting plasma glucose concentration, total cholesterol concentration, HDL cholesterol concentration, triglyceride concentration, uric acid concentration, and hematocrit (model 1) - the relative risk for IFG or Type II diabetes mellitus increased among groups of both non-smokers and ex-smokers as WBC count increased. The multivariate-adjusted relative risk for IFG or Type II diabetes mellitus compared with a WBC count of less than $5.3 \cdot 10^{9}$ cells/ 1 was 1.2 (95\%-CI, 0.6-2.3), 1.6 (CI, 0.8-3.1), and 2.5 (CI, $1.2-5.1$ ) among never smokers $(p$ for trend $=0.009)$ : and 1.0 (CI, 0.4-2.5), 2.3 (CI, 1.0-5.1), and 3.1 (CI, 1.4-7.1) among ex-smokers ( $p$ for trend $=0.001$ ) with WBC counts of 5.3-6.1, 6.2-7.2, and 7.3 $110^{9}$ cells/l or more, respectively. On the other hand, among current smokers, the respective multivariateadjusted relative risks for IFG or Type II diabetes mellitus relative to a WBC count of less than $5.3 \cdot 10^{9}$ cells/l were $1.2(\mathrm{CI}, 0.6-2.1), 1.4$ (CI, $0.8-2.4)$, and $1.3(\mathrm{CI}, 0.8-2.3)$ ( $p$ for trend $=0.313$ ). Additional adjustment for cigarette smoking (model 2) lowered the magnitude of these associations ( $p$ for trend $=0.460$ ).

The risk of IFG or Type II diabetes mellitus by WBC count for those who never smoked and current smokers who did not quit during 6 years of follow-up is shown in Table 3. With the adjustment for various potential predictors of diabetes (model 1 ), the multivariate-adjusted relative risk of IFG or Type II diabe-

Table 2. The risk for incidence of impaired fasting glucose or Type II diabetes mellitus among 2953 Japanese male office workers by smoking status and white blood cell count during 6 years of follow-up

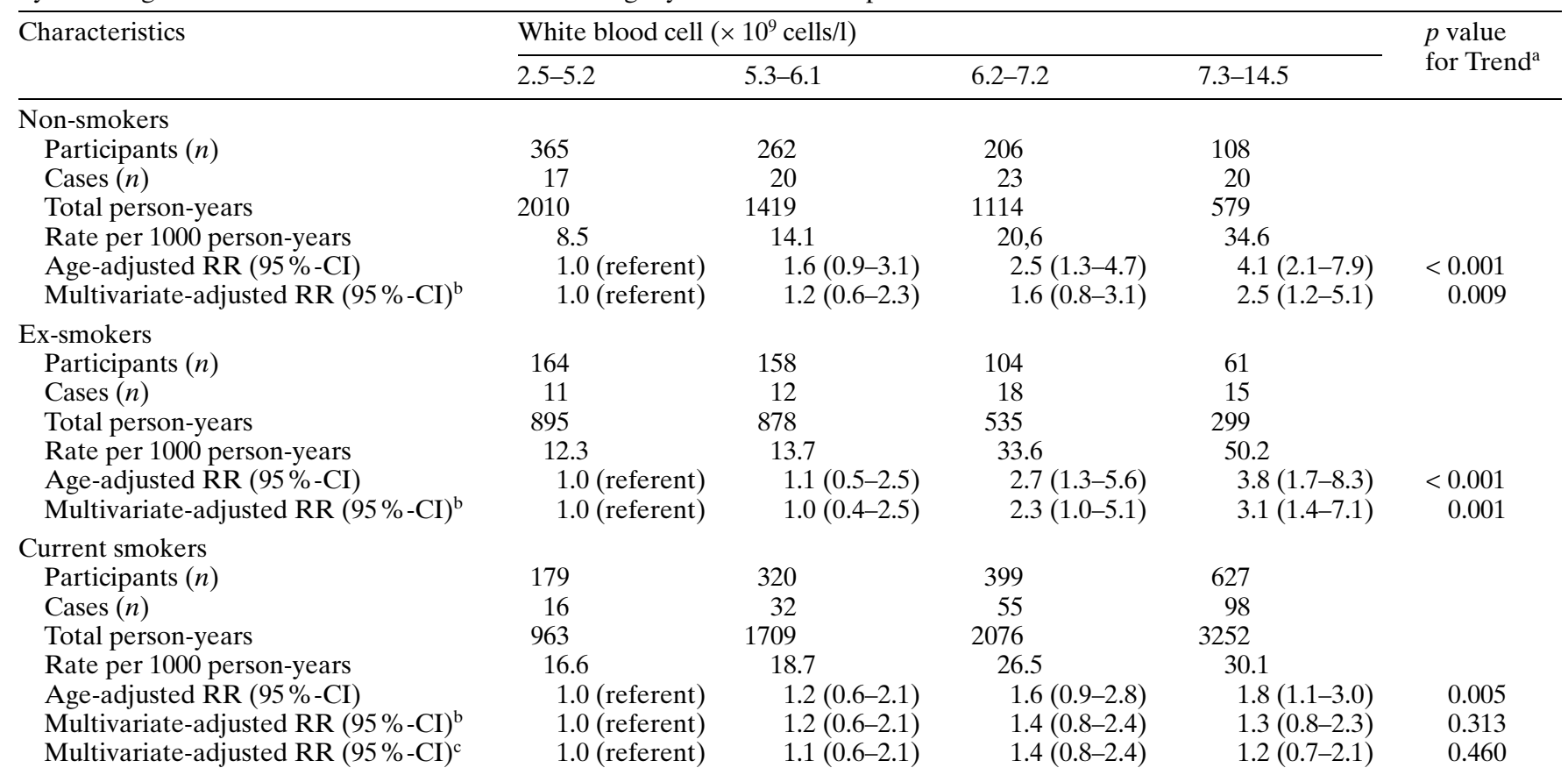

a The test for trend is calculated across increasing categories of white blood cell count

${ }^{\mathrm{b}}$ Adjusted for age, BMI, family history of diabetes, alcohol consumption, regular physical exercise, systolic blood pressure, fasting plasma glucose concentration, total cholesterol concentration, high-density lipoprotein cholesterol concentra-

tion, triglyceride concentration, uric acid concentration and hematocrit at study entry

${ }^{c}$ Adjusted additionally for cigarettes smoked per day at study entry

$\mathrm{RR}$, relative risk 
Table 3. The risk for incidence of impaired fasting glucose or Type II diabetes mellitus by WBC count among non-smokers and current smokers

\begin{tabular}{|c|c|c|c|c|c|}
\hline \multirow[t]{2}{*}{ Characteristics } & \multicolumn{4}{|l|}{ WBC ( $\mathrm{x} 10^{9}$ cells/l) } & \multirow{2}{*}{$\begin{array}{l}p \text { value } \\
\text { for Trend }^{\mathrm{a}}\end{array}$} \\
\hline & $2.5-5.2$ & $5.3-6.1$ & $6.2-7.2$ & $7.3-14.5$ & \\
\hline \multicolumn{6}{|c|}{ Non-smokers who never smoked during the follow-up period } \\
\hline Cases $(n)$ & 16 & 19 & 23 & 18 & \\
\hline Total person-years & 1961 & 1399 & 1100 & 561 & \\
\hline Rate per 1000 person-years & 8.2 & 13.6 & 20.9 & 32.1 & \\
\hline Age-adjusted relative risk $(95 \%-\mathrm{CI})$ & 1.0 (referent) & $1.6(0.8-3.2)$ & $2.6(1.4-4.9)$ & $4.1(2.1-8.1)$ & $<0.001$ \\
\hline \multicolumn{6}{|c|}{ Current smokers who did not quit smoking during the follow-up period } \\
\hline Participants $(n)$ & 133 & 249 & 334 & 552 & \\
\hline Cases $(n)$ & 13 & 30 & 44 & 86 & \\
\hline Total person-years & 699 & 1297 & 1716 & 2853 & \\
\hline Rate per 1000 person-years & 18.6 & 23.1 & 25.6 & 30.1 & \\
\hline Age-adjusted RR (95\%-CI) & 1.0 (referent) & $1.3(0.7-2.4)$ & $1.4(0.8-2.6)$ & $1.6(0.9-2.9)$ & 0.061 \\
\hline Multivariate-adjusted RR $(95 \%-\mathrm{CI})^{\mathrm{b}}$ & 1.0 (referent) & $1.2(0.6-2.3)$ & $1.2(0.6-2.2)$ & $1.2(0.7-2.2)$ & 0.707 \\
\hline
\end{tabular}

a The test for trend is calculated across increasing categories of white blood cell count

${ }^{\mathrm{b}}$ Adjusted for age, BMI, family history of diabetes, alcohol consumption, regular physical exercise, systolic blood pressure, fasting plasma glucose concentration, total cholesterol concentration, high-density lipoprotein cholesterol concentra-

tion, triglyceride concentration, uric acid concentration, and hematocrit at study entry

${ }^{c}$ Adjusted additionally for cigarettes smoked per day at study entry

$\mathrm{RR}$, relative risk

tes mellitus increased in a dose-dependent manner among those who had never smoked and who did not smoke during the follow-up period ( $p$ for trend $=0.010)$, but did not increase among current smokers $(p$ for trend $=0.707)$. Additional adjustment for cigarette smoking (model 2$)$ lessened these associations $(p$ for trend $=0.869)$.

\section{Discussion}

An analysis of the risk for IFG or Type II diabetes according to smoking status showed that in both nonsmokers and ex-smokers, the risk for IFG or Type II diabetes mellitus increased in a dose-dependent manner as WBC count increased. On the other hand, an association between WBC count and the risk of IFG or Type II diabetes was much less clear in current smokers. An association between WBC count and risk for IFG or Type II diabetes mellitus was not observed among current smokers who did not quit smoking during the follow-up period. Our results suggest that WBC count is an important risk factor for IFG or Type II diabetes and that the increased relative risk for IFG or Type II diabetes associated with WBC count is more pronounced in non-smokers.

However, the lower relative risk for IFG or Type II diabetes mellitus associated with WBC count in current smokers does not really mean that cigarette smoking improves the risk for IFG or Type II diabetes mellitus in current smokers. As for the effects of smoking on diabetes, laboratory studies have indicated that cigarette smoking causes insulin resistance in peripheral tissues, whereas insulin secretion may be unimpaired or somewhat overstimulated [27-30]. In an experimental control trial using two oral glucose tolerance tests, smoking acutely impairs glucose tolerance and acutely increases serum insulin and Cpeptide concentrations [31]. Cigarette smoking is also known to stimulate the release of counter-regulatory hormones and consequently cause temporary increase in plasma glucose concentrations [32, 33]. Moreover, recent epidemiologic studies have found the positive association between cigarette smoking and risk for diabetes [6, 7]. Because cigarette smoking had a strong impact on the risk for developing IFG or Type II diabetes in this study (incident rate of IFG or Type II diabetes mellitus among men with a WBC count of $2.5-5.2 \cdot 10^{9}$ cells/l: 8.2 per 1000 person-years for non-smokers and 17.2 per 1000 person-years for current smokers), the influence of WBC count on development of IFG or Type II diabetes mellitus might be obscured by cigarette smoking. As for the association of past smoking with WBC count, WBC count is related to the amount of time passed since quitting, and smokers who quit smoking have a reduced WBC count $[24,25]$. One investigation into the residual effects of smoking on WBC count found that smokers who quit a long time ago had WBC counts more like those who had never used tobacco than those who recently stopped smoking [24] but another study found that long-term ex-smokers still had higher WBC counts than non-smokers [25]. Because we could not examine years since quitting smoking among past smokers during follow-up, the relationship between the effects of the decline in WBC count with time 
since quitting on IFG and Type II diabetes mellitus in our study are less clear.

Our results are consistent with those of other studies $[12,13]$ and indicate that the WBC count is a predictor of IFG or Type II diabetes mellitus because of its association with low-grade inflammation. The mechanism of how WBC count increases the risk for IFG and Type II diabetes mellitus is, however, still not clear. Because insulin reduces the IL-6 mediation of the acute-phase response [34], insulin resistance could lead to higher concentrations of inflammatory markers. IL- 6 has been also shown to be released by adipose tissue, and this release is greater in obese subjects [35]. Furthermore, IL-6 increases postprandially, in parallel to glucose and insulin concentrations in the interstitial fluid of subcutaneous adipose tissue [36]. This increase suggests that the secretion of IL- 6 by adipose tissue might be modulated by food stimuli. Other proinflammatory cytokines, such as TNF- $\alpha$, and leptin produce insulin resistance by influencing the function of the insulin receptor $[37,38]$ or impairing insulin action and inhibiting insulin secretion [39]. The TNF- $\alpha$ could also alter beta-cell function of non-esterified-fatty-acid production [40, 41]. Leptin, aside from possibly having a proinflammatory role [42], impairs insulin action and inhibits insulin secretion [39]. Because WBC counts are increased by cytokines and the lipid pattern of high triglycerides and low HDL cholesterol observed in this study is identical to the features of inflammation [17, 18], the relation of WBC count with development of IFG or Type II diabetes mellitus could be due to the presence of a subclinical inflammatory reaction. However, it is still not clear whether the relation of WBC count with development of IFG or Type II diabetes mellitus is independent of, or mediated by, the presence of concomitant risk factors for diabetes, primarily cigarette smoking [21, 43-46].

Our study had several limitations. Firstly, the WBC count during follow-up was not included in this analysis. Spearman's rank correlation coefficient was $0.691(p<0.001)$ for WBC count between study entry and the date of diagnosis of IFG or Type II diabetes mellitus, or at the end of follow-up. This indicates that those who had the higher WBC count at study entry tended to continue to do so during follow-up. The observed associations between WBC count at baseline and the increased risk for IFG or Type II diabetes mellitus could reflect the effects of WBC count over an observation period.

Secondly, bias in case-finding could have occurred. Specifically, individuals who had higher, but normal WBC counts, are more likely to visit a doctor, thus diabetes could have been found by chance. If annual examinations were required, this assumption should not have an impact in this study.

Finally, persons in our normoglycaemic cohort, particularly those in the older age groups, might not be typical of the general population. Those whose plasma glucose concentration was already above borderline values or who reported taking drugs for hypertension or having a past history of cardiovascular disease during the initial examination were excluded. Because hypertension is a recognized risk factor for diabetes [8. 9], exclusion of hypertensive persons would bias the study toward a particularly healthy study population at a low risk for diabetes. The selection of men with rigorously normal fasting plasma glucose concentration at study entry could have had an effect on the observations.

Despite these potential limitations, our findings, which were obtained from a cohort of middle-aged Japanese men, support the conclusion that higher WBC count - an easily accessed, clinically measured parameter - could predict the development of IFG or Type II diabetes mellitus, primarily in non-smokers.

Acknowledgements. This study was supported in part by a grant-in-aid from the Japan Arteriosclerosis Prevention Fund (JAPF), Tokyo, Japan.

\section{References}

1. Morris RD, Rimm DL, Hartz AJ, Kalkhoff RK, Rimm AA (1989) Obesity and heredity in the etiology of non-insulindependent diabetes mellitus in 32,662 adult white women. Am J Epidemiol 130: 112-121

2. Feskens EJ, Kromhout D (1989) Cardiovascular risk factors and the 25-year incidence of diabetes mellitus in middle-aged men. The Zutphen Study. Am J Epidemiol 130: 1101-1108

3. Helmrich SP, Ragland DR, Leung RW, Paffenbarger RS Jr (1991) Physical activity and reduced occurrence of non-insulin-dependent diabetes mellitus. N Engl J Med 325: 147-152

4. Colditz GA, Willett WC, Rotnitzky A, Manson JE (1995) Weight gain as a risk factor for clinical diabetes mellitus in women. Ann Intern Med 122: 481-486

5. Pan XR, Li GW, Hu YH et al. (1997) Effects of diet and exercise in preventing NIDDM in people with impaired glucose tolerance. The Da Qing IGT and Diabetes Study. Diabetes Care 20: 537-544

6. Rimm EB, Chan J, Stampfer MJ, Colditz GA, Willett WC (1995) Prospective study of cigarette smoking, alcohol use, and the risk of diabetes in men. BMJ 310: 555-559

7. Nakanishi N, Nakamura K, Matsuo Y, Suzuki K, Tatara K (2000) Cigarette smoking and risk for impaired fasting glucose and type 2 diabetes in middle-aged Japanese men. Ann Intern Med 133: 183-191

8. Stolk RP, van Splunder IP, Schouten JS et al. (1993) High blood pressure and the incidence of non-insulin dependent diabetes mellitus: findings in a 11.5 year follow-up study in The Netherlands. Eur J Epidemiol 9: 134-139

9. Hayashi T, Tsumura K, Suematsu C et al. (1999) High normal blood pressure, hypertension, and the risk of type 2 diabetes in Japanese men. The Osaka Health Survey. Diabetes Care 22: 1683-1687

10. Laws A, Reaven GM (1993) Insulin resistance and risk factors for coronary heart disease. Baillieres Clin Endocrinol Metab 7: 1063-1078 
11. Salomaa VV, Tuomilehto J, Jauhinen M et al. (1992) Hypertriglyceridemia in different degrees of glucose intolerance in a Finnish population-based study. Diabetes Care 15: 657-665

12. Schmidt MI, Duncan BB, Sharrett AR et al. (1999) Markers of inflammation and prediction of diabetes mellitus in adults (Atherosclerosis Risk in Communities study): a cohort study. Lancet 353: 1649-1652

13. Freeman DJ, Norrie J, Sattar N et al. (2001) Pravastatin and the Development of Diabetes Mellitus : Evidence for a Protective Treatment Effect in the West of Scotland Coronary Prevention Study. Circulation 103: 357-362

14. Pickup JC, Mattock MB, Chusney GD, Burt D (1997) NIDDM as a disease of the innate immune system: association of acute-phase reactants and interleukin-6 with metabolic syndrome X. Diabetologia 40: 1286-1292

15. Nilsson J, Jovinge S, Niemann A, Reneland R, Lithell H (1998) Relation between plasma tumor necrosis factor-alpha and insulin sensitivity in elderly men with non-insulindependent diabetes mellitus. Arterioscler Thromb Vasc Biol 18: 1199-1202

16. Pickup JC, Crook MA (1998) Is Type II diabetes mellitus a disease of the innate immune system? Diabetologia 41: 1241-1248

17. Sim E (1993) Humoral factors. IRL Press, Oxford

18. Memon RA, Feingold KR, Grunfeld C (1997) Cytokines and intermediary metabolism. In: Remick DG, Friedland JS (eds) Cytokines in health and disease, 2nd edn. Marcel Dekker, New York, pp 381-399

19. Reaven GM (1988) Banting lecture 1988. Role of insulin resistance in human disease. Diabetes 37: 1595-1607

20. Facchini F, Hollenbeck CB, Chen YN, Chen YD, Reaven GM (1992) Demonstration of a relationship between white blood cell count, insulin resistance, and several risk factors for coronary heart disease in women. J Intern Med 232: 267-272

21. Targher G, Seidell JC, Tonoli M, Muggeo M, De Sandre G, Cigolini M (1996) The white blood cell count: its relationship to plasma insulin and other cardiovascular risk factors in healthy male individuals. J Intern Med 239: 435-441

22. Corre F, Lellouch J, Schwartz D (1971) Smoking and leucocyte-counts. Results of an epidemiological survey. Lancet 2: 632-634

23. Friedman GD, Siegelaub AB, Seltzer CC, Feldman R, Collen MF (1973) Smoking habits and the leukocyte count. Arch Environ Health 26: 137-143

24. Petitti DB, Kipp H (1986) The leukocyte count: associations with intensity of smoking and persistence of effect after quitting. Am J Epidemiol 123: 89-95

25. Sunyer J, Munoz A, Peng Y et al. (1996) Longitudinal relation between smoking and white blood cells. Am J Epidemiol 144: 734-741

26. The Expert Committee on the Diagnosis and Classification of Diabetes Mellitus (1997) Report of the Expert Committee on the Diagnosis and Classification of Diabetes Mellitus. Diabetes Care 20: 1183-1197

27. Facchini FS, Hollenbeck CB, Jeppesen J, Chen YD, Reaven GM (1992) Insulin resistance and cigarette smoking. Lancet 339: 1128-1130

28. Attvall S, Fowelin J, Lager I, Von Schenck H, Smith U (1993) Smoking induces insulin resistance - a potential link with the insulin resistance syndrome. J Intern Med 233: 327-332

29. Eliasson B, Attvall S, Taskinen MR, Smith U (1994) The insulin resistance syndrome in smokers is related to smoking habits. Arterioscler Thromb 14: 1946-1950

30. Ronnemaa T, Ronnemaa EM, Puukka P, Pyorala K, Laakso M (1996) Smoking is independently associated with high plasma insulin levels in nondiabetic men. Diabetes Care 19: 1229-1232

31. Frati AC, Iniestra F, Ariza CR (1996) Acute effect of cigarette smoking on glucoce tolerance and other cardiovascular risk factor. Diabetes Care 19: 112-118

32. Cryer PE, Haymond MW, Santigo JV, Shah SD (1976) Norepinephrine and epinephrine release and adrenergic mediation of smoking-associated hemodynamic and metabolic events. N Eng J Med 295: 573-577

33. Sandberg H, Roman L, Zavodnick J, Kupers N (1973) The effect of smoking on serum somatotropin, immunoreactive insulin and blood glucose levels of young adult males. J Pharmacol Exp Ther 184: 787-791

34. Campos SP, Baumann H (1992) Insulin is a prominent modulator of the cytokine-stimulated expression of acutephase plasma protein genes. Mol Cell Biol 12: 1789-1797

35. Mohamed-Ali V, Goodrick S, Rawesh A et al. (1997) Subcutaneous adipose tissue releases interleukin-6, but not tumor necrosis factor-alpha, in vivo. J Clin Endocrinol Metab 82: 4196-4200

36. Orban Z, Remaley AT, Sampson M, Trajanoski Z, Chrousos GP (1999) The differential effect of food intake and beta-adrenergic stimulation on adipose-derived hormones and cytokines in man. J Clin Endocrinol Metab 84: 2126-2133

37. Uysal KT, Wiesbrock SM, Marino MW, Hotamisligil GS (1997) Protection from obesity-induced insulin resistance in mice lacking TNF-function. Nature 389: 610-614

38. Hotamisligil GS, Peraldi P, Budavari A, Ellis R, White MF, Spiegelman BM (1996) IRS-1-mediated inhibition of insulin receptor tyrosine kinase activity in TNF-alpha- and obesity-induced insulin resistance. Science 271: 665-668

39. Girard J (1997) Is leptin the link between obesity and insulin resistance? Diabetes Metab 23: 16-24

40. Corbett J, Serup P, Bonner-Weir S, Nielsen JH (1997) Betacell ontogeny: growth and death. Diabetologia 40 [suppl 3]:B27-B32

41. Unger RH (1995) Lipotoxicity in the pathogenesis of obesity-dependent NIDDM. Genetic and clinical implications. Diabetes 44: 863-870

42. Loffreda S, Yang SQ, Lin HZ et al. (1998) Leptin regulates proinflammatory immune responses. FASEB J 12: 57-65

43. Wilson PW, Garrison RJ, Abbott RD, Castelli WP (1983) Factors associated with lipoprotein cholesterol levels. The Framingham Study. Arteriosclerosis 3: 273-281

44. Hansen LK, Grimm RH, Neaton JD (1990) The relationship of white blood cell count to other cardiovascular risk factors. Int J Epidemiol 19: 881-888

45. Friedman GD, Tekawa I, Grimm RH, Manolio T, Shannon SG, Sidney S (1990) The leucocyte count: correlates and relationship to coronary risk factors: the CARDIA study. Int J Epidemiol 19: 889-893

46. Kannel WB, Anderson K, Wilson PW (1992) White blood cell count and cardiovascular disease. Insights from the Framingham Study. JAMA 267: 1253-1256 